\title{
Quizás... Beckett
}

Gabriela García Hubard

Universidad Nacional Autónoma de México, México

Fecha de recepción: 1 de noviembre de 2020.

Fecha de aceptación: 20 de junio de 2021.

\section{Resumen}

Este texto aborda las diferentes huellas de los escépticos griegos en la obra de Beckett, principalmente en La Trilogía. A partir de la actitud eféctica que evoca el Innombrable desde el principio del texto, se analizan las posibilidades de leer estas referencias filosóficas como inserciones irónicas que desestabilizan la noción de intencionalidad. De la mano de Linda Hutcheon se proponen otras formas de entender las ironías beckettianas.

Palabras clave: eféctico, escepticismo, suspensión, ironía, intencionalidad, Hutcheon.

\section{Maybe... Beckett}

\begin{abstract}
This text deals with the different traces of the Greek sceptics in Beckett's work, mainly in The Trilogy. Based on the ephectic attitude evoked by the Unnameable from the beginning of the text, we analyse the possibilities of reading these philosophical references as ironic insertions that destabilize the notion of intentionality. Following the work of Linda Hutcheon, other ways of understanding beckettian ironies are proposed.
\end{abstract}

Keywords: scepticism, ephectic, suspension, irony, intentionality, Hutcheon.

1. Este artículo es un producto vinculado al proyecto PAPIME 400219 "Literatura angloirlandesa contemporánea de los siglos XX y XXI" de la Universidad Nacional Autónoma de México. 
Temporalité du discours (de la conduite) sceptique : il y a des temps pour rien [...] il s'agit de défaire le temps du système, d'y mettre des moments de fuite, d'empêcher que le système prenne.

Roland Barthes (216)

Todos nos hemos preguntado alguna vez qué hacer y cómo proceder al comienzo de un texto, y más aún cuando nos enfrentamos a un inicio como el de L'Innommable. En cambio, no resulta tan común decidir proceder a través de puras aporías, como lo hace el personaje-narrador desde el primer párrafo, al ofrecernos una suerte de introducción o guía de lectura:

Comment faire? comment vais-je faire, que dois-je faire dans la situation où je suis, comment procéder? Par pure aporie ou bien par affirmations et négations infirmées au fur et à mesure, ou tôt ou tard. Cela d'une façon générale. Il doit y avoir d'autres biais. Sinon ce serait à désespérer de tout. Mais c'est à désespérer de tout. À remarquer, avant d'aller plus loin, de l'avant, que je dis aporie sans savoir ce que ça veut dire. Peut-on être éphectique autrement qu'à son insu? Je ne sais pas. $(1953, \mathrm{pp} .7,8)$

Como todos sabemos la palabra "aporía" viene del griego a-poros y significa literalmente dificultad para pasar, o en su acepción más común impasse, camino teórico bloqueado, por lo que en la filosofía se identifica con una dificultad lógica insuperable, sin embargo, como lo demuestra Rodolphe Gasché, para los griegos no se trataba de una simple privación o de algo impracticable, ya que al confrontarse a las aporías se debía buscar un poros, "un camino para salir de la situación difícil e intolerable"2 (2002, p.107), apareciendo así desde Platón como un motor indispensable para todo pensamiento filosófico. Pero Gasché también pone el acento en el hecho que, según Heidegger, para Aristóteles este proceso (o experiencia aporética) que debería conducir al conocimiento comienza cuando, frente a la dificultad, reconocemos nuestra propia ignorancia.

Fue dentro de este contexto que busqué demostrar (García 2008a) que la aporía en la obra de Beckett puede ser leída como ese momento que conduce al reconocimiento de la propia ignorancia: "Mais est-ce là des apories, des vraies? Je ne sais pas", dice Malone antes de agregar: "D’ailleurs peu importe que je sois né ou non, que jaie vécu ou non, que je sois mort ou seulement mourant, je ferai comme jai toujours fait, dans l'ignorance de ce que je fais, de qui je suis, d’où je suis, de si je suis." (pp. 10 y 85). De igual forma, cuando la ignorancia empieza a invadir tanto al narrador como a su personaje, Molloy confiesa: "Moi-même, à condition d'y réfléchir, je l'ignorerais" (11). Así, lejos de escapar a la ignorancia los personajes beckettianos parecen aferrarse a ella, ignorando irónicamente su propia ignorancia. Al igual que muchos otros personajes beckettianos, el Innombrable también admite con frecuencia su propia ignorancia pero, a diferencia de tantos otros, vincula esta falta de conocimiento a la aporía, ejecutando magistralmente el deseo beckettiano de trabajar con la impotencia y la ignorancia: "The kind of work I do is one in which I am not master of my material" admitió el escritor tres años después de la publicación de L'Innommable, refiriéndose a la distinción entre Joyce y su propia escritura:

[t]he more Joyce knew the more he could. His tendency is towards omniscience and omnipotence as an artist. I'm working with impotence, ignorance [...] There seems to be a kind of aesthetic axiom that expression is an achievement - must be an achievement. My little exploration is that whole zone of being that has always been set aside by artists as something unusable - as something by definition incompatible with art. (Beckett citado por Boxall, 2000, pp.96,97 el subrayado es mío). 
¿Cómo podemos interpretar esta ignorancia en alguien que multiplica las referencias textuales e intertextuales, a veces tan eruditas e innumerables, provenientes tanto de la literatura como del psicoanálisis, la teología, la filosofía...? Ciertamente no se puede considerar la ignorancia en Beckett como una simple falta de conocimiento, así como tampoco se puede pensar en sus aporías como la simple negación del camino. Del mismo modo ¿cómo entender que un autor tan perfeccionista y obsesivo (como lo demuestran sus múltiples borradores), tan controlador de sus representaciones dramáticas, confiese que 'no controla el material' del trabajo que realiza?

Si bien es cierto que desde el principio el Innombrable decide proceder a través de puras aporías sin saber lo que eso significa, también es verdad que este gesto parece ser una actitud eféctica, aunque no tenga la certeza de poder hacerlo de forma intencional. $Y$ es precisamente la relación que existe entre las palabras 'aporie’ y 'éphectique' una de las primeras razones por las que la ignorancia del Innombrable no implica simplemente la falta de conocimiento, aunque tampoco parece conducir a él, como Aristóteles y Heidegger hubieran deseado. De hecho, esta relación nos obliga a volver la mirada hacia el padre del escepticismo: Pirrón ${ }^{3}$, y sus discípulos, que se dieron a sí mismos los nombres de efécticos y aporéticos (entre otros): mientras que los discípulos efécticos siempre suspenden su juicio, los discípulos aporéticos son inciertos, al no haber encontrado la verdad (Brochard, 1959, p.70).

En nuestros días, reduciendo el escepticismo griego, coloquialmente decimos que alguien es escéptico en cuanto duda, y podríamos decir en este sentido que tanto Beckett como sus personajes y narradores muestran un alto nivel de escepticismo: "Voyant probablement que je restais sceptique, Mahood laissa tomber comme incidemment qu' il me manquait non seulement une jambe, mais un bras aussi" (58), añade el Innombrable. Aunque esta referencia explícita al escepticismo pueda entenderse como una simple duda, la palabra 'probablemente', que hace que la duda (nuevamente) así como el resto de la oración no sean seguras, muestra una vacilación irónica sobre el escepticismo que impregnará todo el trabajo de Beckett.

Es importante anotar que estas referencias explícitas a los sabios de la antigüedad apelan a la complejidad y a la pluralidad que ha acechado siempre a la historia misma de los escépticos, y al mismo tiempo atestiguan, una vez más, la forma en que Beckett opera, con tanta frecuencia, a través de sus constantes referencias a la filosofía. Dicho de otra forma, las referencias filosóficas en la obra de Beckett sufren una suerte de apropiación, expropiación y transformación (Derrida diría exapropiación), a la vez que se desvían de una reducción simplista y obvia.

Muchos estudios se han realizado sobre la relación de la obra beckettiana con la filosofía, Lucas Margarit nos recuerda que Ruby Cohn desde principios de los años 60 explica la forma en que Beckett trabaja con la filosofía sin sumarse a un sistema determinado, tomando a veces solo palabras o fragmentos, construyendo "una poética desde el desmembramiento de sus lecturas, en este caso filosóficas" (Margarit, 2015, p. 51). Sin embargo, este proceder no es un simple juego literario o ficticio, sino que construye y muestra una postura frente a la realidad: "Beckett retoma y reformula los fragmentos filosóficos que pueden combinar con su poética y con su manera de concebir el mundo a través de su obra" (Margarit, 2015, p. 69).

3. Actualmente sabemos, gracias a las notas filosóficas de Beckett, que leyó a los escépticos. En la página 122 anota: "scepticisme, three stages of scepticism : 1 the older scepticism, 2 newer academy, 3 later scepticism" y en la página 123, redacta una nota sobre "The ataraxy of Pyrrho". Finalmente, en la página 124 escribe: "criteria of truth (Stoics. Epicureans, Sceptics,)", y en las páginas 174-175, “Epicureanism Scepticism”. (Frost, 2006, p. 84, 86). 
Michael E. Mooney también recuerda que desde los años 70, autores como Hesla y Rosen subrayaron la influencia de los primeros pensadores griegos en su obra, y en consecuencia los personajes beckettianos no solo se piensan en eco con Chaplin y Keaton, sino que pueden ser considerados como arquetipos de la antigüedad: Diógenes y Demócrito (1982, p. 215). Mooney reconoce la forma en que Beckett utiliza muchas ideas filosóficas y las desacredita al mismo tiempo, pues le encantaban las bromas filosóficas y las anécdotas, por lo que "la mezcla de seriedad y ligereza es difícil de separar" (216). Por ello, el riesgo consiste en que si lo leemos con mucha seriedad como si cada eco filosófico fuera una declaración, sería una gran injusticia, y si lo leemos sin importancia, perdemos en gran parte los cruces ricos y complejos que surcan su obra. En un tono similar al de Margarit, este teórico evoca el toque cómico de Beckett frente a la filosofía, conformando así lo que tiene que decir sobre la capacidad humana de comprender el mundo. (Mooney, p. 216)

Feldman por su parte, en el artículo "Beckett and Philosophy 1928-1938" argumenta que, aunque Beckett haya buscado deslindarse de la filosofía occidental a principios de los años 60, diciendo que no leía filosofía porque el lenguaje de Heidegger y Sartre le resultaba muy filosófico y no lo entendía, en realidad durante diez años (de 1928 a 1938) leyó y estudió un número considerable de textos filosóficos, por lo que su 'deuda' con muchos de ellos es indiscutible, y diversos temas filosóficos van a ser recurrentes a lo largo de toda su obra. Para Feldman, la relación de Beckett con la filosofía antes de esa década era más bien superficial y el mismo Beckett reconoció que de sus lecturas consiguió un 'botín verbal' para su primera novela (Feldman, 2010, p. 177).

En las Philosophy notes que Beckett escribió entre las dos guerras, las cuales se encuentran en el Trinity College de Dublín, Feldman encontró algunos de los libros y nombres de filósofos que parecen más relevantes para el corpus beckettiano: Greek Philosophy, Part I: Thales to Plato (1914) de John Burnet; A Short History of Philosophy (1907) de Archibald Alexander; A History of Philosophy de Wilhelm Windelband ${ }^{4}$. Y resalta de la última etapa la obra de Geulincx, no sin antes haber pasado por Spinoza, Pascal, Descartes, Kant y Leibniz, sin olvidar, evidentemente a Schopenhauer, entre otros. De sus notas filosóficas también retoma, como lo han trabajado otros críticos, las palabras de Vico "not everything is intelligible to men" (citado por Feldman, 2010, p. 168).

Ahora bien, en nuestro contexto, resulta apodíctico resaltar, de las Philosophy notes, además de la presencia de los escépticos a la que le dedicaremos una parte de nuestro análisis, la importancia del texto "Critique of Knowledge" de Fritz Mauthner, una de las principales figuras (junto con Schopenhauer, Nietzsche y Wittgenstein) del "escepticismo lingüístico" que tanto llamó la atención de Beckett. Porque si es verdad que Beckett buscó borrar su relación con la filosofía declarando que trabajaba con la ignorancia, lo cual resultó francamente enigmático para muchos críticos (Feldman, 163), también parece correcto aceptar junto con Feldman, que Beckett adopta "lo que Fritz Mauthner llamó "learned ignorance"' (166), que no es lo mismo que una simple ignorancia.

Dirk Van Hulle hace un breve recuento de lo que se ha dicho sobre la relación entre la compleja actitud que tenía Beckett con el lenguaje y sus lecturas de Mauthner: Ben-Zvi por ejemplo, habla de "la imposibilidad de verificación y la imposibilidad de demostrar esta imposibilidad" y John Pilling dijo que Mauthner le ofreció a Beckett todo para "destruir cualquier sistema de pensamiento, incluso el 'irracionalismo"' (2011, p. 211). Van Hulle también recuerda que para Schopenhauer ("one of the ones that mattered most” según Beckett) la filosofía había abusado de abstracciones y conceptos generales, 
uniendo lo incompatible y separando lo inseparable (212), mientras que Nietzsche (hablando sobre el lenguaje) atacaba frontalmente el concepto filosófico:

What then is truth? A movable host of metaphors, metonymies, and anthropomorphisms: in short, a sum of human relations which have been poetically and rhetorically intensified, transferred, and embellished, and which, after long usage, seem to a people to be fixed, canonical and binding. Truths are illusions which have forgotten are illusions - they are metaphors that have become worn out and have been drained of sensuous force, coins which have lost their embossing and are now considered as metal and no longer coins. (Nietzsche citado por Van Hulle, p. 213)

Sin embargo, pese a las múltiples coincidencias entre Beckett y el "escepticismo lingüístico", desde los años 80 Linda Ben-Zvi señaló lo poco apropiado que resulta llamar a Beckett 'Mauthnerian' porque "implicaba una posición derivada de Beckett y una simplificación excesiva de Mauthner' Según Ben-Zvi, el propio Beckett advirtió contra este tipo de encasillamientos" (Van Hull, p. 226) y pese a todo, los críticos siguen cayendo en estas trampas.

Pero ¿podemos decir lo mismo sobre la relación de Beckett con el escepticismo?, ¿podemos escapar al encasillamiento? Mientras que John Calder se refirió a Beckett como el último de los estoicos, Feldman señala que en realidad se encuentra más cerca de los escépticos, y para confirmarlo evoca de nuevo las notas filosóficas de Beckett de los años 1932-33 en donde insiste que los escépticos resisten la seducción de la opinión y la acción: el escéptico, anota Beckett "knows that nothing can be affirmed as to phenomena, that no opinion may be assented to, and so restrains himself from judgment, and thereby from action. In the suspension of judgment, he finds imperturbability, rest within himself, ataraxy. The sceptics were called 'The Suspenders"' (citado por Feldman, p. 167).

En este contexto, Mooney asegura que, pese a la presencia de Descartes en la obra de Beckett, la ficción puede entenderse mejor a partir de su relación con Demócrito y el escepticismo de Sexto Empírico (215). Pero el problema con el texto de Mooney es que termina por contradecirse, lo cual es recurrente en otros textos que abordan la relación de Beckett y la filosofía: por un lado reconoce la actitud cómica de los narradores frente a los sistemas dogmáticos y aclara que a través de su crítica no quiere reducir la filosofía a una ficción, ni tampoco busca transformar la ficción en filosofía; aunque reconoce que la estética de Beckett se nutre de una fuente escéptica, metamorfoseando una serie de ideas y pastiches presocráticos, termina aseverando cosas como que "el escepticismo de Beckett es tradicional. Sus solipsistas, desde Murphy pasando por Watt, Molloy, Malone y el Innombrable, cada uno desea alcanzar el estado que los escépticos llamaron ataraxia, la calma interior apática que resulta de la aporía, o la duda escéptica, y de la suspensión del juicio eféctica." ¿Dónde quedó entonces la metamorfosis, el pastiche, y la actitud cómica? ¿Por qué Monney no considera la ironía que alberga la pregunta del Innombrable sobre la actitud eféctica? Aunque Mooney admite que Murphy nunca consigue la ataraxia que busca, parece tomarse muy en serio las referencias filosóficas al insistir que el personaje "traiciona el cartesianismo para revelar su lealtad con el escepticismo" (217-18), concluyendo que Beckett transforma el material filosófico en imágenes literarias (218), y que en Murphy "las perspectivas filosóficas se convierten en puntos de vista estéticos" (222), pues para el crítico todos los personajes comparten una actitud escéptica.

Pese a las innumerables huellas filosóficas, y la evidente predilección de Beckett por ciertos pensadores, para nosotros resulta imposible aceptar que sus textos mantengan una lealtad con alguno de ellos. Es por esto que queremos preguntar ¿por qué en la poética de Beckett con tanta frecuencia los críticos reconocen la imposibilidad de señalar un sistema filosófico estable, pero paradójicamente terminan por encajonarlo con 
algún pensador?, ¿qué es lo que genera esta ambigüedad tan recurrente? Para tratar de responder a estas preguntas regresemos pues a las marcas explícitas de la antigüedad griega en la obra de Beckett, pues como dijo Derrida en La diseminación, uno de los libros que mejor conjuga la relación entre literatura y filosofía: "Nous intéressent moins ici ces propositions de forme philosophique que le mode de leur réinscription dans le texte" (Derrida, 1972, p. 256).

Además de la referencia directa al escepticismo que mencionamos hace un momento, en la obra de Beckett encontramos varias nociones que hacen resonar sugestivamente la antigüedad griega. Algunas son mencionadas repetidamente tales como aporía, afasia, apatía y ataraxia; y otras solo aparecen una vez, aunque adquieren una relevancia particular debido a su rareza, como la palabra eféctico. En algunos momentos es obvio que el primer grupo de palabras puede incluso representar una composición rítmica, como sucede en la logorrea de Lucky: "un Dieu personnel quaquaquaqua... qui du haut de sa divine apathie sa divine athambie sa divine aphasie nous aime bien à quelques exceptions" (Beckett, 1952, p. 55), sin embargo se trata de conceptos que comparten simultáneamente una larga historia entre varias escuelas filosóficas, tanto modernas como antiguas, cuyos significados provocan diferentes lecturas en la obra de Beckett. Al igual que la afasia ${ }^{5}$, la historia de la apatía se divide entre su sentido actual de insensibilidad, su sentido particular de impasividad o calma del alma entre los estoicos, como la ausencia de sufrimiento en Aristóteles, como el objetivo de la epojé para los escépticos, sin olvidar su significado patológico que indica un estado depresivo, inercia o indiferencia a las emociones y los deseos. ¿Cómo interpretar entonces la 'apatía divina' de la que habla Lucky?

Del mismo modo, la ataraxia, que significa la ausencia de trastornos, la tranquilidad del alma y, por lo tanto, promete ser un principio de felicidad para los sabios de las diversas escuelas filosóficas de la antigüedad, ¿qué provoca en la obra beckettiana? Pensamos por ejemplo en la ataraxia a la que llega Molloy, aunque deba enfrentarse a las "espiègleries de la nature" (55); o la ataraxia de Watt (207) que, al extenderse, termina cubriendo el jardín, las plantas e incluso al mismo Arthur, como si fuera una enfermedad contagiosa.

Además, como ya lo había señalado el mismo Beckett en sus notas filosóficas, es a través de la suspensión del juicio o reserva con respecto a una opinión que el escéptico puede alcanzar la apatía o la ataraxia, es decir, la tranquilidad del alma. Sin embargo, podemos encontrar nuevamente en Beckett un desvío cuando esta tranquilidad o ataraxia dura tan poco tiempo que parece imposible. Recordemos el momento en que Watt comienza a llorar mientras sale a la calle justo después de su instante de ataraxia; de la misma manera, después de la calma y la ataraxia que alcanzó Molloy, "cest l’angoisse du retour" (55); ¿cómo podemos olvidar que, incluso si nada puede molestar al Innombrable, está constantemente inquieto (11)?

Ahora bien, cabe señalar que la palabra eféctico que significa en griego la suspensión del juicio, es un concepto que no comparte su historia, en otras palabras, aparece como un concepto exclusivamente escéptico. Por lo tanto, desde el principio habría que preguntarse: ¿Cómo leer esta referencia explícita del escepticismo griego en la Trilogía? ¿Sus personajes y narradores son escépticos en el sentido del escepticismo griego? ¿Podemos decir que el ideal de los primeros escépticos, como Pirrón o Timon, de aferrarse a uno mismo, vivir de manera simple y modesta como los humildes, sin pretensiones de ningún

\footnotetext{
5. Para una revisión profunda de las afasias en la obra de Beckett, ver el artículo "Les aphasies beckettiennes" (García 2008 b), en el que también se aborda la riqueza no solo filosófica, sino interdisciplinaria de esta noción y la forma como en la obra de Beckett desestabiliza la idea de intencionalidad. Este cuestionamiento encuentra una fuerte resonancia con la última parte de nuestro análisis sobre la ironía que presentamos aquí.
} 
tipo, y dejar pasar el mundo (Brochard, p.59), encuentra un eco entre algunos personajes beckettianos? Además, ¿quién está acostumbrado a oponer dos hipótesis contrarias sobre cualquier tema para declarar su incapacidad de pronunciarse: Ænesidème, Molloy, el Innombrable? ¿Quién examina las hipótesis que nadie ha imaginado formular: los escépticos, los narradores beckettianos? ¿Quién ha escrito sobre el "desacuerdo de los sentidos y de la inteligencia”, Sexto Empírico, Beckett? La costumbre de Carnéades de no concluir, por citar solo un ejemplo, ¿nos parece recurrente?

Efectivamente las dudas, la indiferencia, el sarcasmo, la incertitud, lo indiscernible, las contradicciones e incluso a veces la impasibilidad que muestran a menudo los personajes y narradores beckettianos son gestos propios del escepticismo. Sin embargo, si la resignación, la renuncia, el reposo y sobre todo el silencio son también gestos característicos del primer escepticismo, bien sabemos que los personajes de Beckett nunca logran realizar tales actos, no tanto porque no lo quieran, sino más bien porque no pueden hacerlo. Del mismo modo, mientras los escépticos no dudan de los fenómenos ni de su pensamiento, alguien como el Innombrable irá tan lejos como para dudar de su propio pensamiento cuando se pregunta "avec quoi jugerais-je?" (108), "avec quoi aurais-je une opinion ?" (197). De hecho el personaje parece más radical que los escépticos cuando llega a cuestionar sus propios sentimientos y percepciones; en pocas palabras: "Il ne suffit pas pour être sceptique, de parler quelquefois comme un sceptique" (Brochard, p.24).

Hasta aquí hemos visto que por momentos los narradores beckettianos se acercan y en otros se alejan del escepticismo. Con esta misma ambivalencia, la oración del Innombrable que señalamos desde el inicio ("Peut-on être éphectique autrement qu'à son insu? Je ne sais pas"), muestra que, tanto la pregunta como la respuesta, nos llevan a una indecisión irónica y desestabiliza cualquier garantía basada en la posibilidad misma de ser eféctico. Aunque el narrador parece asumir este pensamiento escéptico de la suspensión, no parece compartir el presupuesto sobre la conciencia. Si la suspensión escéptica se presenta como una decisión explícita, consciente e intencional, la pregunta del Innombrable supone irónicamente que la condición apropiada de la actitud eféctica puede hacerse "à son insu", sin el conocimiento del sujeto, para investigar más tarde si puede ser eféctico de alguna otra forma. De esta manera, el Innombrable presenta una especie de suspensión escéptica que no será ni puramente intencional, ni simplemente sin su conocimiento. ¿Podemos decir entonces que suspende la suspensión? "Je ne sais pas" sería su propia respuesta. Sin embargo, el narrador parece lograr un cierto tipo de suspensión a través de la repetición y desarticulación de esas "affirmations et négations infirmées au fur et à mesure, ou tôt ou tard", explorando la suspensión a través del lenguaje, mientras pone y retira.

Es entre todos estos desajustes que podemos encontrar otro eco entre esta suspensión a través del lenguaje y la insatisfacción con el lenguaje mismo tanto en el escritor como en los escépticos: mientras que para Ænesidema el lenguaje lo obliga a usar fórmulas que todavía son demasiado afirmativas y para Sexto Empírico (Brochard, p.294) el lenguaje, siendo dogmático, se presta poco a la expresión de las ideas escépticas, sabemos que Beckett se quejó, entre otras cosas, de "that terrible materiality of the word Surface" (Beckett, 1983, p.172), lo que llevó a Knowlson a hablar de la desconfianza beckettiana respecto al lenguaje (1996, p.672). Por lo tanto, puede ser que las "expresiones elípticas" de las que habla Sexto Empírico resuenen en la "forma elíptica de hablar" (25) de Molloy, así como las interrogantes que encontramos en lugar de proposiciones afirmativas en el filósofo (Sextus Empiricus, 1997, p.157), nos recuerdan lo indiscernible de las preguntas constantes beckettianas.

Elipsis, cuestionamientos, suposiciones, pero también "ni oui ni non", "je ne sais rien", "je ne définis rien", "pas plutôt ceci que cela", "tout est incompréhensible" son también 
expresiones escépticas que conciernen a la suspensión del asentimiento, y que encontramos continuamente en Beckett, a veces irónicamente acompañada de ese momento de ataraxia de Molloy: "Je pouvais donc l'interroger sans fin et sans danger, dit Molloy. Car ne rien savoir, ce n'est rien, ne rien vouloir savoir non plus, mais ne rien pouvoir savoir, savoir ne rien pouvoir savoir, voilà par où passe la paix, dans l'âme du chercheur incurieux" (85). ${ }^{6}$

Recordemos una vez más las primeras cuatro páginas de L'Innommable, otro ejemplo de esta incertidumbre que desencadena formulaciones de tipo escéptico: "impossible de le savoir", "je n’ai pas d’opinion", "je ne sais pourquoi" y sobre todo los "peut-être" o más bien "le suprême peut-être" (Beckett, 1953, p.44) ${ }^{7}$ que, aunque exaspera al narrador ${ }^{8}$, sigue siendo inevitable y demasiado presente en la Trilogía desde Molloy; y, finalmente, el "je ne sais pas" de la suspensión propia de la actitud eféctica. Irónicamente, este 'no saber' se mezcla o incluso se confunde con la ignorancia (o más bien la 'ignorancia aprendida'), el olvido y la mala memoria de los personajes: mientras el Innombrable no sabe si está por quedarse o por salir, poco importa cómo sucede cualquier cosa, "dire cela, sans savoir quoi", ni dónde, ni cuándo ni quién; el personaje parece estar hablando de él, pero en realidad no es él. Molloy, por su parte, tampoco sabe mucho, ya que desconoce si su madre está muerta, si lo que está haciendo ahora es mejor, no sabe con qué pensamos... y, en particular, tampoco sabe cómo decir las cosas y lo que significan algunas palabras. Los "je ne sais pas", por lo tanto, no son tan fortuitos como podrían parecer, ni literariamente ni filosóficamente en relación con el lenguaje beckettiano: "je dirai, je ne sais pas" (9), dice el Innombrable, donde no podemos estar seguros de que vaya a decir simplemente "No sé", o si no sabe lo que va a decir. En este punto, Grossman señala acertadamente la suspensión del sentido o del significado con respecto a la escritura beckettiana: "se trata menos de la invención de palabras, la neología tan profusa, que de una sintaxis paradójica que pone las palabras en un equilibrio inestable y las abre como frases sobre una multiplicidad de significados en suspenso" (Grossman, 2004, pp.5 y 6). ${ }^{9}$

Por lo tanto, no es sorprendente que en la sintaxis paradójica de los narradores beckettianos persista el rastro del escepticismo que duda y disputa la verdad, la certeza y la esencia, entre otros. Recordemos el momento en que Molloy, hablando de la verdad, confiesa: "pour ma part je ne massocierai jamais à une telle perversion" (102). Pero un rastro no implica ninguna lealtad, ni asumir un sistema como tal. ¿Qué sucede si al leer nuestra cita inicial, en donde aparece la palabra eféctico, no solo ponemos atención a la proposición filosófica del escepticismo, sino que también le damos importancia a su modo de reinscripción en el texto? Nos damos cuenta, como lo hemos mencionado en múltiples momentos en este texto, que la ironía ocupa un lugar ineludible en la obra de Beckett en general, y en la actitud eféctica del Innombrable en particular.

La noción de ironía aparece con frecuencia en los textos críticos sobre la obra de Beckett, pero pocas veces ocupa un lugar central. Esto se debe, quizás, al carácter resbaladizo de la ironía, pues son raros los trabajos que definen la noción con precisión, y a menudo se utiliza como un adjetivo superficial. La RAE por ejemplo, nos dice que

\footnotetext{
6. Tantos ejemplos que podríamos dar: “Ce que jaffirme, nie, mets en doute, au présent, je peux le faire encore aujourd'hui. Mais j’emploierai surtout les diverses formes du passé. Car le plus souvent je ne suis pas sûr, ce nest peut-être plus ainsi, je ne sais pas encore, ne sais pas tout court, ne saurai peut-être jamais." (Beckett, 1951b, p. 143.)

7. De alguna manera me gustaría que este artículo pudiera leerse en eco con el texto "Quizás... Barthes y Derrida" (García 2019), pues junto al "pensamiento del quizás" de Derrida y el "discurso del quizás" de Barthes, lo que podemos llamar "la literatura del quizás’ de Beckett encuentra un lugar privilegiado.

8. “Assez de peut-être aussi. Ce moyen est usé. Je vais tout m’interdire" (Beckett, 1953, p.42).

9. Otro ejemplo, menos escéptico y más poético, nos lo ofrece Margarit: "En el verso: That's not moving, that's moving, donde por medio de un juego de palabras, vemos que la acción se presenta en forma ambigua por su sentido reflexivo, es decir, que el verbo to move puede ser interpretado como mover o conmoverse" (55).
} 
se trata de una burla fina y disimulada, o que es "una expresión que da a entender algo contrario o diferente de lo que se dice". Por su parte, Helena Beristáin en su Diccionario de retórica y poética (1992), explica que se trata de una "figura de pensamiento porque afecta a la lógica ordinaria de la expresión", y aunque al final admite que no siempre implica una burla, su definición principal agrega que "consiste en oponer, para burlarse, el significado a la forma de las palabras en oraciones, declarando una idea de tal modo que, por el tono, se pueda comprender otra, contraria", e insiste no solo en el carácter de oposición, sino también en el verdadero sentido que se oculta tras una ironía: "Se trata del empleo de una frase en un sentido opuesto al que posee ordinariamente, $y$ alguna señal de advertencia en el contexto lingüístico próximo revela su existencia y permite interpretar su verdadero sentido". (271) Beristáin también menciona otros estudios sobre el tema que ven en la ironía una reacción ante el mundo, o un simple juego estimulante. Y aunque reconoce que las marcas que permiten interpretar una ironía pueden ser ambiguas, su postura refuerza la idea del 'verdadero sentido': "Siempre la ironía es interpretada en su verdadero sentido gracias a algún grado de evidencia significativa que se halla en el contexto discursivo [...]" (272).

¿Qué podemos decir entonces sobre las ironías de El innombrable? ¿Cuál es el verdadero sentido cuando el personaje ignora irónicamente su propia ignorancia o suspende irónicamente la suspensión? La definición que acabamos de revisar sobre la ironía parece no ayudarnos mucho con los textos de Beckett, y esto precisamente lo que analiza Jennifer Jeffers en "Beyond Irony: The Unnamable's Appropriation of its Critics in a Humorous Reading of the Text" (1995). En este artículo, Jeffers critica las lecturas irónicas que se han hecho de la obra de Beckett, en particular las que llama 'la ironía romántica' y 'la ironía humanista, pues dice que "cada enfoque se basa en una interpretación tradicional de la ironía socrática que se caracteriza por 'decir lo contrario de lo que quieres decir' y se basa en una lectura estable y abierta del texto" (49). En cambio, la autora argumenta acertadamente que no se puede apropiar o reducir el texto de Beckett a un sentido estable. Cuando considera la definición tradicional de la ironía, es el lector inteligente quien interpreta la ironía: el opuesto de lo dicho, es decir lo no dicho, y pareciera que la intención es la del autor.

Jeffers critica que ambas aproximaciones o interpretaciones de la ironía (la romántica y la humanista), aunque de diferente forma, traducen el texto en un discurso con sentido, mientras que para ella muchos textos de Beckett, "no 'tienen sentido' en lo que tradicionalmente se acepta como 'buen sentido' o 'sentido común"”10 (54). Y apoyándose en Deleuze, prefiere poner el acento en el humor de la ironía, el cual juega en la superficie del lenguaje de forma horizontal y rizomática, a diferencia de la definición tradicional de ironía que busca el sentido debajo de la superficie del lenguaje (54).

En una lectura humorística el 'sinsentido' no es una falta de sentido, sino simplemente un sentido diferente del que el orden de la representación reconoce como sentido o 'buen sentido'. El sinsentido o el absurdo son expresiones utilizadas en el existencialismo o en la 'filosofía del absurdo' en las que el sentido del que hablan depende de una interpretación estable del sentido, del 'buen sentido', pero ese sentido falta en el mundo, por lo tanto, el existencialista lamenta la ausencia, la pérdida, el declive o la deficiencia esencial del sentido en el mundo. Una definición del sinsentido deleuziano, indicaría la sobreabundancia de sentido en cualquier significación dada. Nunca hay poco sentido, siempre se produce demasiado sentido (Jeffers, 55 ).

10. Este argumento se encuentra en sintonía con la vieja disputa entre Adorno y Esling, la cual se puede consultar en forma de resumen en el texto de Boxall. 
Para Jeffers, el Innombrable pervierte el concepto tradicional de representación y del sentido, a través de una parodia de la búsqueda irónica de la identidad y del conocimiento. Acusando a las lecturas tradicionales de no leer el texto, dice que el humor inicia un tipo de lectura (con su texto) que permite una multiplicidad y libera la obra de Beckett de las otras apropiaciones críticas.

Ahora bien, pese a lo sugerente de esta lectura, nos parece que con su análisis también pretende apropiarse el texto al rechazar tajantemente las otras lecturas y reducirlas a tan solo dos grupos, como si no existieran otras aproximaciones a través del llamado postestructuralismo u otras teorías de finales del siglo XX. Para abordar el tema de la ironía, el talón de Aquiles de esta propuesta radica en que no toda ironía es necesariamente humorística, como lo demuestra Linda Hutcheon en Irony's Edge (1994), uno de los estudios más completos y propositivos de las últimas décadas. Y es a partir de este libro que podemos hablar de una noción de ironía no tradicional que nos ayude a responder algunas preguntas que nos hemos planteado en este recorrido.

Aunque Hutcheon reconoce que lo más interesante de la ironía es su naturaleza transideológica (10), a nosotros nos gustaría resaltar la pertinencia de su estudio en nuestro contexto por dos razones: primero, por la manera en que retoma y cita los textos más relevantes escritos hasta ese momento en torno a la ironía, haciendo una suerte de síntesis, antes de desmarcarse de muchos de ellos; segundo, por la forma como cuestiona el funcionamiento tradicional de la ironía, para poner el acento en la problemática de la intencionalidad que subyace cada vez que la ironía 'sucede'.

Dependiendo como opere, la ironía puede usarse tanto para cuestionar o socavar como para reforzar o legitimar, puede ser un arma o hacernos sentir incómodos y, por lo mismo, Hutcheon no la trata como un tropo retórico limitado, ni tampoco como algo tan extendido como una actitud ante la vida, "sino como una estrategia discursiva que opera a nivel del lenguaje (verbal) o de la forma (musical, visual, textual)" (10). Es por esto que, lo que más le interesa es el aspecto social e interactivo de su funcionamiento. Hutcheon señala que siempre se ha dicho que hay un ironista (intencional) y su audiencia, pero desde el principio de su libro se pregunta ¿qué hacemos con las ironías que se interpretan como tal pero que nadie provoca?, y viceversa, pues también sucede que uno pretende a veces ser irónico, pero nadie lo percibe.

Hutcheon está consciente de que no podemos tratar el aspecto semántico de la ironía de forma aislada, pues siempre hay que considerar al receptor y el entorno. Es el receptor (intencionado o no) quien va a decidir si hay o no ironía y la va a interpretar, y esto ocurre sin importar las intenciones del ironista, lo cual la hace dudar sobre quién debería ser designado como ironista. El aspecto más resbaladizo del significado de la ironía, casi siempre se ha tratado de anclar en la intención del ironista, por lo que en su trabajo propone ampliar el concepto de intencionalidad. Que la intencionalidad ya no garantiza el sentido, se sabe desde hace tiempo, y también sabemos que el sentido no es unívoco. Es este aspecto de la ironía, el replanteamiento de la intencionalidad (que también evidenciamos en la actitud eféctica del Innombrable), el que puede ayudarnos a responder la pregunta que nos hicimos al inicio cuando Beckett asegura: "The kind of work I do is one in which I am not master of my material", pues la única forma de que el escritor no domine su trabajo implicaría socavar radicalmente la noción de intencionalidad. Por lo tanto, en este contexto podemos señalar dos vías: la declaración de Beckett es irónica, o las constantes ironías en sus textos provocan que no tenga el control absoluto del sentido.

Normalmente quien busca crear una ironía lo hace con lo que dice y lo que no dice, pero no siempre lo logra; no hay garantía de que aquella persona que interpreta va a entender la intención de la ironía. Frente a la ironía, insiste Hutcheon, no se trata 
simplemente de decodificar o de reconstruir el 'verdadero' sentido, el sentido oculto, si esto fuera así, el tema sería menos polémico. El aspecto indirecto de la ironía "complica considerablemente los diversos modelos existentes de comunicación intersubjetiva entre un hablante y un oyente. Con la ironía, existen en cambio relaciones dinámicas y plurales entre el texto o enunciado (y su contexto), el llamado ironista, el intérprete y las circunstancias que rodean la situación discursiva" (11).

Si bien reconoce que la ironía sucede entre lo dicho y lo no dicho, para ella el sentido irónico siempre es otro y más que lo dicho, por lo que constantemente hace las cosas más complejas, y nunca logra desambiguar ${ }^{11}$. Hutcheon también admite que es muy raro que la ironía sea un simple mensaje invertido (89), y "es posible pensar en la ironía no como decir una cosa y significar otra, sino como un proceso de comunicación que permite que dos o más significados se jueguen al mismo tiempo, uno contra el otro" (45). El sentido de la ironía es simultáneamente doble o múltiple, y por lo tanto no tenemos que rechazar el sentido literal para llegar al sentido irónico o 'real' de la frase (60). Cuando interpretamos la ironía oscilamos muy rápido entre lo dicho y lo no dicho; el sentido de la ironía es un flujo, no está fijo, por eso la teórica nos invita a dejar de pensarla en términos binarios: either/or o de la sustitución de un sentido irónico por uno literal (66).

Este proceso complejo tiene consecuencias, como la incomodidad que muchas veces suscita; según Kundera, la ironía irrita "because it denies us our certainties by unmasking the world as an ambiguity" (Kundera citado por Hutcheon, 15), pero también puede burlarse, atacar, ridiculizar, excluir, avergonzar y humillar; puede provocar furia o placer. A estas alturas se antoja preguntar ¿no estará Hutcheon hablando acaso directamente de la literatura beckettiana? Para la teórica, la ironía es un juego muy serio que apunta a las complejidades de la realidad social y de la historia, sin embargo, como su atribución y su interpretación pueden ser diferentes, retomando a Fish nos dice que la ironía es un "risky business" (11); su potencial para desestabilizar es enorme, pero siempre está el riesgo de que sea interpretada en un sentido erróneo o incluso inverso (31).

Hacia el final del texto podemos ver que, en lugar de poner el peso en el ironista o en el intérprete, para Hutcheon se trata sobre todo de una relación compleja entre las condiciones de producción y las condiciones de interacción en un contexto en donde se entrecruzan comunidades discursivas. En este sentido, las ironías de la obra de Beckett también dependen de las diferentes comunidades discursivas que buscan elucidarlas: por un lado están los expertos en traducción, por otro los estudiosos de la literatura inglesa o francesa, los especialistas en filosofía o en psicoanálisis, los versados en historia o las autoridades del teatro, entre otras. Todos tenemos conocimientos diferentes y pertenecemos a diferentes comunidades discursivas y muchas veces, como reconoce Hutcheon, se sobreponen las comunidades y por eso no hay consenso. No obstante, la ironía tampoco encuentra estabilidad al interior de estos círculos, pues como asegura Culler: "contexts are just as much in need of elucidation as events" (citado por Hutcheon, p. 145), dicho de otra forma, también los contextos se interpretan.

Si consideramos que la ironía tradicional es elitista porque requiere diferentes tipos y niveles de participación, y supone un conocimiento superior por parte del intérprete capaz de leer correctamente el texto, entonces se habla de ingenuos y sofisticados;

11. Para Hutcheon, gracias al impacto del postestructuralismo y a la imposibilidad de un sentido estable y unívoco, la ironía se ha visto privilegiada, pues ambos señalan la naturaleza problemática del lenguaje (57). En este sentido, no estaría lejos de lo que Jeffers nos dice citando a Deleuze: "This situation depicts Deleuze's definition of paradox: 'Good sense affirms that in all things there is a determinable sense or direction (sens); but paradox is the affirmation of both senses or directions at the same time' (Logic 1); also paradoxes "always have the characteristic of going in both directions at once, and of rendering identification impossible...' (Logic 75)”. (Jeffers, p.63). 
incompetentes y competentes; ignorantes y conocedores; la masa y los informados. Frente a esta jerarquización nos atrevemos a sugerir que el Innombrable, al ignorar irónicamente su propia ignorancia y al suspender irónicamente la suspensión, está deconstruyendo la noción tradicional de ironía, eliminando así el carácter elitista. Finalmente, para leer a Beckett no necesitamos pertenecer a ninguna de las comunidades discursivas que acabamos de mencionar, y el placer de la lectura no parece distinguir entre ignorancia e ignorancia aprendida.

Sería muy arriesgado decir que todas las referencias filosóficas de la obra de Beckett pueden leerse desde la ironía entendida en los términos de Hutcheon, pero sí podemos abrir la posibilidad de revisar, en este contexto, sus modos de reinserción en cada texto. Mientras tanto, podemos aventurarnos a sugerir que el escepticismo del Innombrable no escapa a las complejidades que se entretejen en este modo de proceder. Es por esto que para unos Beckett subvierte las ideas filosóficas, y para otros asume un sistema; para unos el Innombrable es escéptico, para otros satiriza a los sabios de la antigüedad y para los demás su burla del escepticismo (siendo escéptico con el escepticismo) realiza una mise en abyme de la suspensión.

Para terminar, nos gustaría agregar que, si la ironía en la obra beckettiana tiene un objetivo o una víctima, se trata tanto del lenguaje como del conocimiento. Lo sabemos desde la carta alemana del 37 en donde propone realizar 'un asalto a las palabras' y a 'todo el conocimiento' (Beckett, 1984, p.173). Quizás Beckett estaría contento de saber que, para Fischer, por ejemplo, la ironía es lo que define la condición actual del conocimiento. En conclusión, si nada garantiza la comprensión de la ironía, retomando el espíritu eféctico de El innombrable, así como la influencia del 'escepticismo lingüístico', tenemos que reconocer que nada garantiza esa garantía, por eso quisimos recordar las palabras de Vico en las notas de Beckett: "not everything is intelligible to men". 


\section{Q Bibliografía}

" Barthes, Roland. (2002). Le Neutre, Cours au Collège de France (1977-1978), Paris: Seuil / Imac.

» Beckett, S. (1951a). Molloy. Paris: Minuit.

» Beckett, S. (1951b). Malone meurt. Paris: Minuit.

» Beckett, S. (1952). En attendant Godot. Paris: Minuit.

»Beckett, S. (1953). L'Innommable, Paris: Minuit.

»Beckett, S. (1953). Watt. London: Calder, 1998.

»Beckett, S. (1983). Disjecta. London: Calder.

"Beristáin, H. (1992). Diccionario de retórica y poética. México: Porrúa.

» Boxall, P. (Ed). (200o). Samuel Beckett, Waiting for Godot / Endgame, Cambridge: Icon Books.

»Brochard, V. (1959). Les Sceptiques grecs, Paris: Librairie Général de Français, 2002.

»Derrida, J. (1972) La dissémination, Paris: Seuil.

» Feldman, M. (2010) “Beckett and Philosophy, 1928-1938”. En Samuel Beckett Today / Aujourd'hui, Vol 22, pp. 163-18o.

»Frost, Everett et Jane Maxwell, "Catalogues of Notes Diverse Holo[graph] and of Samuel Beckett Manuscripts at Trinity College Library Dublin" (2006). En Samuel Beckett Today / Aujourd'hui 16, 84-86.

»García Hubard, G. (2008a). “'Sa naissance fut sa perte’ et la perte son aporie: Heidegger / Beckett / Derrida”. Samuel Beckett Today / Aujourd'hui. Núm. 19, pp. 451-461. https://www.jstor.org/stable/25781852?seq=1

" García Hubard, G. (2008bn) “En traversant l'aphasie”. Samuel Beckett Today / Aujourd'hui, núm. 20, pp. 335-345. https://www.jstor.org/stable/25781882?seq=1

»García Hubard, G. (2019). "Quizás... Barthes y Derrida”. Acta Poética, UNAM, pp. 63-85, Enero-Junio. https://revistas-filologicas.unam.mx/acta-poetica/ index.php/ap/article/view/846/1095

» Gasché, R. (2002). “L'expérience aporétique aux origines de la pensée: Platon, Heidegger, Derrida", Tr. Georges Leroux, Études Françaises 38.1-2, "Derrida Lecteur », éd. Ginette Michaud y Georges Leroux, Les Presses de l'Université de Montréal.

"Grossman, E. (2004). "Une " Audace Folle »", Europe, Jacques Derrida, Paris, Mai, pp. 3-8.

" Hutcheon, L. (1994). Irony's Edge. London: Routledge.

» Jeffers, J. (1995). “Beyond Irony: The Unnamable's Appropriation of its Critics in a Humorous Reading of the Text". en The Journal of Narrative Technique, Winter, Vol. 25, No.1, pp. 47-66.

»Knowlson, J. (1996), Damned to Fame, The Life of Samuel Beckett. London: Bloomsbury. op. cit., p. 672. 
"Margarit, L. (2015). “Samuel Beckett y el pensamiento post-cartesiano: el caso Geulincx en Samuel Beckett”. En La mostración de lo inefable. Coord. Javier Corona Fernández y Gergana Petrova, Universidad de Guanajuato, pp. 49-74.

"Mooney, M. E (1982). “Presocratic scepticism: Samuel Beckett's Murphy reconsidered”. ELH, Spring, Vol. 49, No. 1, pp. 214-234.

»Sextus Empiricus. (1997) Esquisses pyrrhoniennes, tr. Pierre Pellegrin Paris: Seuil.

"Van Hulle, D. (2011). “'Eff it': Beckett and linguistic skepticism”. En Sofia Philosophical Review, Vol. V, No. 1.

»Van Hulle, D. y Nixon, M. (2013). Samuel Beckett’s Library, Cambridge University Press. 